\title{
Understanding the Fintech Hype
}

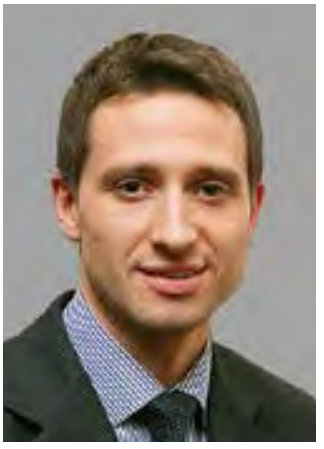

By Rhodri Preece, CFA

"Fintech" is one of the most talked about buzzwords in finance these days. It headlines many industry conferences and events worldwide and has even found its way onto the international regulatory agenda. The hype around fintech alludes to its potential to lower costs, increase process efficiencies, and facilitate access to financial products and markets. Yet knowledge of fintech is mixed, and the scope of its application to investment management remains unclear. Will it have a disruptive impact on the industry, and which investors will benefit?

In simple terms, fintech comprises three main developments: (1) the application of distributed ledger (blockchain) technology in finance; (2) automation in the provision of financial advice (robo-advisers); and (3) loan-based or capital-raising platforms that directly connect issuers and investors (disintermediating the traditional role of banks), including crowdfunding platforms and peer-to-peer (marketplace) lending.

The applicability of these three elements to investment management is most developed in the case of robo-advisers. Automated financial advice tools have gained a foothold in the market in recent years, offering the potential for relatively low-cost, standardized investment solutions. Robo-advisers operate similarly to traditional human advisers, providing portfolio solutions for individuals' financial needs based on their risk tolerances, investment horizons, and other preferences. The difference is that robo-advisers generate recommendations algorithmically using these inputs.

To understand the effects of automation on financial advice, as well as the application of other fintech issues, CFA Institute conducted a member survey in February-March 2016. We received 775 responses from our survey pool (a very high response rate of $20 \%$ ) and published the results in April. The survey found that more than $70 \%$ of respondents think mass affluent investors will be positively affected by automated financial advice tools through reduced costs, improved access to advice, and improved product choices. This finding supports the anecdotal observation that roboadvisers target the lower-end passive investment market.

Mass Affluent

Other Investors

HNW

Institutional Investors

Ultra High Earners

* Excludes not sure
At the same time, respondents found it unlikely that automated financial advice tools will gain traction for ultrahigh-net-worth and institutional investors, with $71 \%$ and $63 \%$ of respondents, respectively, indicating these groups would not be affected by automated advice. The implication is that financial advice to these market segments is by nature highly tailored and thus less amenable to standardized portfolio solutions provided by robo-advisers. These investors, who usually have large portfolios and potentially diverse and complex investment needs, are likely to continue to favor personalized, human advice.

Similarly, when asked about the extent to which automated financial advice tools will replace engagement with human advisers, $67 \%$ of respondents thought that institutional investors would not be affected at all, and $70 \%$ thought the same for ultra-high-net-worth investors. In contrast, $88 \%$ of respondents thought mass affluent investors would somewhat or entirely replace human advisers with automated services.

Overall, these findings are consistent with the conclusions of the Financial Advice Market Review (FAMR) published by the UK Financial Conduct Authority and Her Majesty's Treasury in March 2016. The FAMR noted that steps needed to be taken to make the provision of advice to mass-market investors more cost effective and included a proposal to help firms bring mass-market automated advice models to market more quickly. These conclusions suggest that robo-advisers could fill an "advice gap" that has opened up in consumer segments seeking to avoid high upfront fees for financial advice. This situation is particularly relevant in the United Kingdom following the ban on commission-based advice in favor of fee-based services under the Retail Distribution

\section{Investors affected by automated financial advice tools*}

Positively affected Not affected Negatively affected

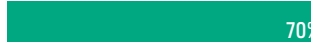

$70 \%$

$13 \%$

$17 \%$

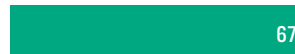

$67 \%$

$15 \%$

$18 \%$

$41 \%$

$46 \%$

$13 \%$

$24 \%$

$63 \%$

$13 \%$

$21 \%$ $71 \%$ $9 \%$

$0 \%$

$20 \%$

$40 \%$

$60 \%$

$80 \%$

$100 \%$

Question: How will the following investors be affected by automated financial advice tools? 
Review that came into force on 31 December 2012.

Despite the positive sentiment expressed, survey respondents highlighted certain concerns associated with the provision of automated financial advice. When asked about risks, respondents cited flaws in automated financial advice algorithms as the biggest risk introduced by robo-advisers ( $46 \%$ of respondents, a plurality), followed by mis-selling (30\%) and privacy and data protection concerns (12\%). Additionally, respondents were split between those who believe that incidences of market fraud and mis-selling would be made worse via the growing prevalence of automated financial advice tools and those who think such risks will diminish. Nearly half (47\%) of all respondents expected the quality of service to be negatively affected, versus $37 \%$ who thought it would improve.

When asked which aspect of fintech will have the greatest effect on the financial services industry, respondents considered robo-advisers to be the most impactful in one year and five years from now. However, the greatest change between the two time horizons relates to the application of blockchain technology, exhibiting a 17 percentage point increase. This finding suggests that blockchain has significant potential in the medium to long term as the scope of its application becomes clearer. Among possible applications, respondents considered clearing and settlement, alternative currencies, commercial banking, fund administration, asset servicing, and capital markets infrastructure as areas that could be moderately or significantly impacted by blockchain technology.

\section{DISCIPLINARY NOTICES}

\section{REVOCATION}

Effective 28 March 2016, CFA Institute imposed a Revocation of membership and of the right to use the CFA designation on James Ming Pui Poon (Hong Kong), a charterholder member. CFA Institute found that Poon violated the Code of Ethics and Standards of Professional Conduct I(A) - Knowledge of the Law; I(C) - Misrepresentation; I(D) - Misconduct; and VI(A) - Disclosure of Conflicts (2005 and 2010).

During the period 2005 to 2011, Poon was employed by China International Capital Corporation (Hong Kong) Limited (CICCHK) and Yuanta Securities (Hong Kong) Company Limited (Yuanta). From October 2005 to February 2008, Poon was the managing director of CICC Securities' Sales and Trading Department. In February 2008, he joined CICC Asset Management and became managing director of the Asset Management Department. In August 2009, Poon left CICCHK and became a director and president of Yuanta.

In January 2014, the SFC banned Poon from re-entering the securities industry in Hong Kong for 10 months. The SFC found that during the relevant five-year period, Poon conducted extensive personal

\section{Greatest impact on financial services industry, by timeline*}

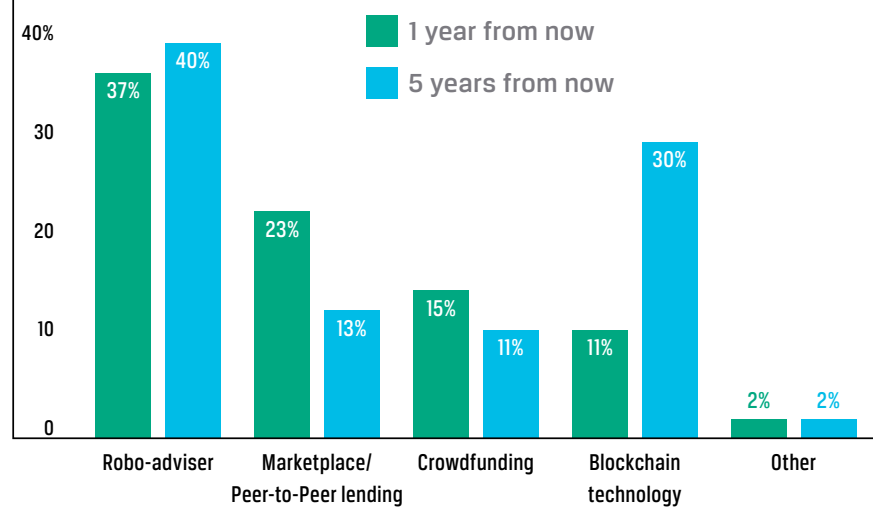

Question: Which technology do you see as having the greatest impact on the financial services industry 1 year and 5 years from now?

* Excludes not sure

The survey findings have supported our engagement with regulators and policymakers as they begin to explore ways to support fintech's development and to ensure its consistency with existing conduct of business and investor protection standards. CFA Institute will

KEEP GOING

"Fintech Survey Report," www.cfainstitute.org/Survey/ fintech_survey.pdf

"Survey: Ultra HNW, Institutional Clients

Prefer Humans to Robo-Advisers,"

Market Integrity Insights blog [http://cfa.is/1SmZI4p] stay engaged in the debate as fintech gains prominence in shaping our industry's evolution.

Rhodri Preece, CFA, is head of capital markets policy for EMEA at CFA Institute.

trading in several securities accounts belonging to two of his friends while intentionally concealing such activities from his employers, CICCHK and Yuanta, in violation of General Principle 1 of the Code of Conduct for Persons Licensed by or Registered with the SFC.

Starting in June 2005 , Poon secretly bought a total of 30 million shares of an energy company for his own benefit, using his two friends' securities accounts. In July 2007, Poon sold the shares and received two checks totaling HK\$25.6 million. Poon used the remaining money in the accounts to trade 83 different securities (excluding the energy company) until the accounts were closed in April 2011. Poon later admitted to the SFC that all of the shares in the friends' accounts were bought and sold at his direction and secretly belonged to him.

According to the SFC, Poon knowingly and intentionally violated the written policies and procedures of CICCHK and Yuanta, which required that employees disclose their outside securities accounts and holdings both before joining the firm and annually. The firms also required that all personal trading by Poon be pre-approved in writing by both his supervisors and the firms' compliance departments. The SFC found that Poon deliberately and dishonestly concealed from his employers his beneficial interests and trading activities in his friends' accounts by preparing and submitting annual declarations and acknowledgement forms that he knew were false and misleading.

Poon's misconduct, which was repeated numerous times and continued over a period of more than five years, prevented CICCHK and Yuanta from properly monitoring his personal trading to detect and prevent market manipulation and insider trading. Such monitoring is of crucial importance in protecting the integrity of the financial markets.

\section{SUMMARY SUSPENSION}

On 12 November 2015, CFA Institute imposed a Summary Suspension on Leng Hung Lam (Republic of Singapore), a lapsed charterholder member, automatically suspending his membership and right to use the CFA designation. Because Lam did not request a review, the Summary Suspension became a Revocation on 12 December 2015.

On 21 0ctober 2015, Lam was found guilty of 